\title{
Pneumocephalus following breathalyzer use
}

\author{
Konan Edmond Kouame, MD • Kryste Chancel Mahoungou Guimbi, MD • \\ Yapo Paul Yapo, MD
}

Received: 19 December 2014/ Accepted: 15 January 2015 / Published online: 27 January 2015

(c) Canadian Anesthesiologists' Society 2015

\section{To the Editor,}

We report a case of a 37-yr-old male who developed pneumocephalus following use of a breathalyzer (the patient provided consent for publication of this report). The patient had a history of traumatic basal skull fractures and left frontal subdural hematoma for which he received surgery. Two months following the surgery, he underwent a titanium cranioplasty of the basal skull. The patient had to undergo reoperation one year later to evacuate an epidural empyema, at which time the titanium cranioplasty was removed. During a routine roadside police check two months following the reoperation, the patient had to blow into a breathalyzer to ascertain his blood alcohol level. A few hours after the test, he felt a subcutaneous swelling on his forehead (Fig. 1), and a computed tomography scan performed four days later showed frontal epidural pneumocephalus communicating with frontal subcutaneous emphysema (Fig. 2).

Pneumocephalus often occurs after surgical evacuation of a subdural hematoma, but it can also occur as a result of various other intracranial operations. ${ }^{1,2}$ In the case of a basal skull dural defect, the occurrence of high air pressure in the nasal cavity may cause pneumocephalus, and it has

K. E. Kouame, MD ( $\varangle)$ - K. C. Mahoungou Guimbi, MD Surgical Intensive Care and Anesthesia Department, CHR Orleans, Orleans, France e-mail: drkouame@gmail.com

Y. P. Yapo, MD

Surgical Intensive Care and Anesthesia Department, CHU Abidjan, Abidjan, Ivory Coast

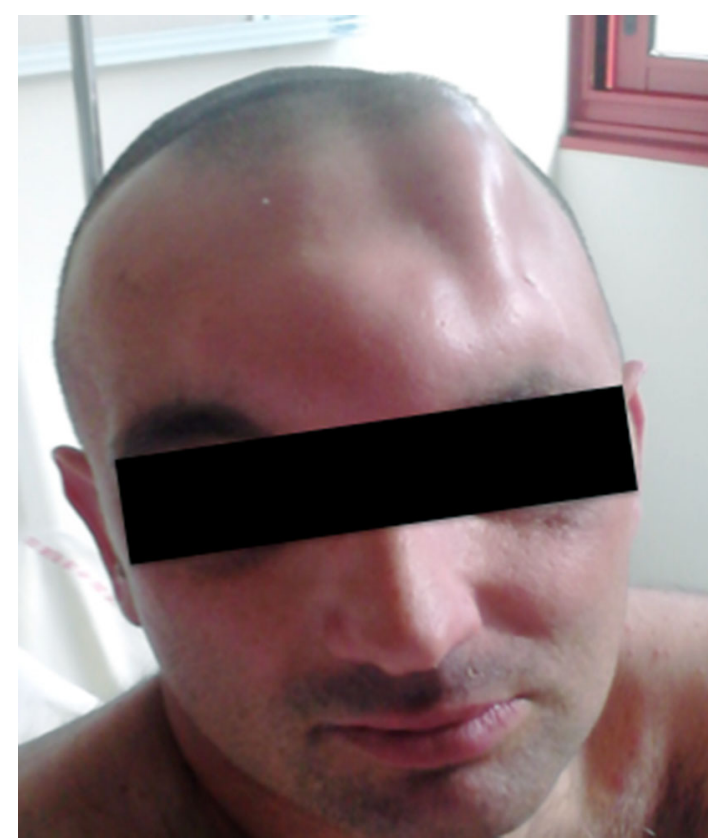

Fig. 1 Subcutaneous swelling in the left frontal region

been reported during sneezing or with the use of noninvasive ventilation after neurosurgery. ${ }^{3}$ In our patient, the strong expiratory effort needed to inflate a single-use breathalyzer likely caused significant increases in airway pressure in the nasal cavity that may have reopened a healing dural defect. This case represents a unique occurrence of such a complication caused by the use of a breathalyzer, and it speaks to the potential danger of any high nasal airway pressures (e.g., during use of spirometry, continuous positive airway pressure, or in this case, a breathalyzer) during the early postoperative period after basal skull surgery. 


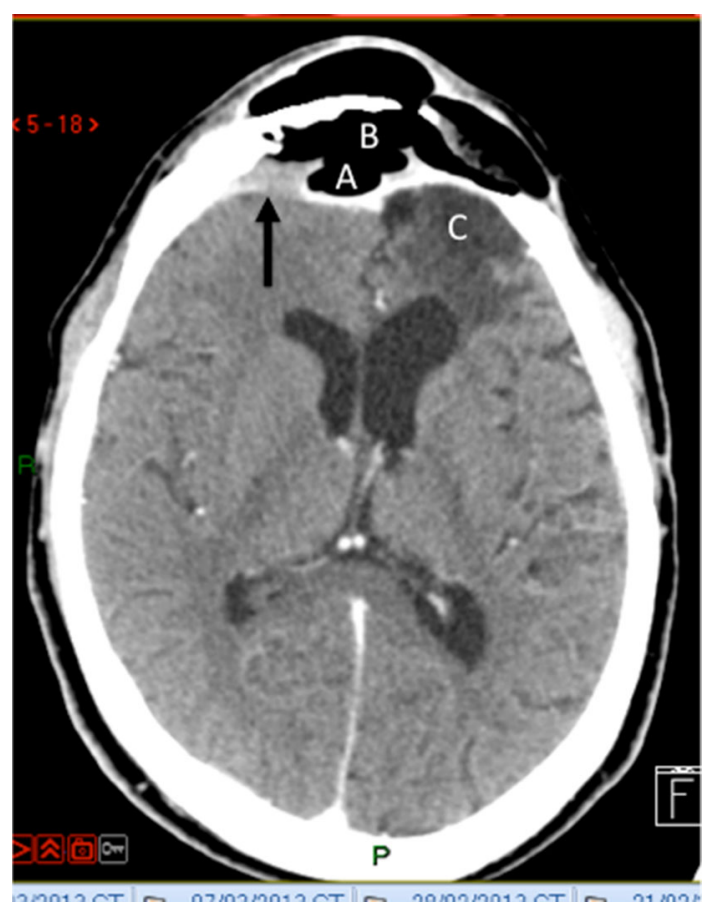

Fig. 2 Brain computed tomography scan showing the frontal sinus (A), the epidural pneumocephalus (B), and the abscess (C). The arrow indicates the dural border
Acknowledgements Dr. Thierry Boulain, Medical Intensive Care Department; Dr. Didier Rea, Surgical Intensive Care and Anesthesia Department; and Dr. Bertrand Muckensturm, Neurosurgery Department, CHR Orleans, France.

Conflicts of interest None declared.

\section{References}

1. Artru AA. Nitrous oxide plays a direct role in the development of tension pneumocephalus intraoperatively. Anesthesiology 1982; 57: 59-61.

2. Michel SJ. The Mount Fuji sign. Radiology 2004; 232: 449-50.

3. Zlotnik D, Taylor G, Simmoneau A, Viot-Blanc V, Devys JM. Two cases of pneumocephalus following noninvasive continuous positive airway ventilation after transsphenoidal neurosurgery (French). Ann Fr Anesth Reanim 2014; 33: 275-8. 